\title{
Measurements of UV aerosol optical depth in the French Southern Alps
}

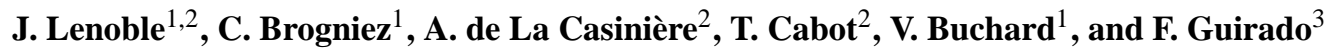 \\ ${ }^{1}$ Laboratoire d'Optique Atmosphérique (LOA), Université des Sciences et Technologies de Lille, 59655 Villeneuve d'Ascq \\ Cedex, France \\ ${ }^{2}$ Interactions Rayonnement Solaire Atmosphère (IRSA), Université Joseph Fourier de Grenoble, 17 Quai Claude Bernard, \\ 38000 Grenoble, France \\ ${ }^{3}$ Centre Européen Médical et Bioclimatologique de Recherche et d'Enseignement Supérieur (CEMBREU), 35, rue Croix de \\ Bretagne, Villars St Pancrace, 05100 Briançon, France
}

Received: 29 November 2007 - Published in Atmos. Chem. Phys. Discuss.: 8 January 2008

Revised: 29 September 2008 - Accepted: 29 September 2008 - Published: 17 November 2008

\begin{abstract}
Routine measurements of global and diffuse UV irradiances at Briançon station (1310 $\mathrm{m}$ a.s.l.) are used to retrieve the direct solar irradiance and the aerosol optical depth (AOD), for cloudless days. Data of three years (2003, 2004, 2005) are analyzed; the results confirm those of a preliminary analysis for 2001, 2002.

The atmosphere is very clear in winter, with AODs between 0.05 and 0.1 . The turbidity increases slowly in spring, starting end of February, with AODs around 0.2-0.3 in mid summer, some values reaching 0.4. A similar behaviour is observed for all years, with somewhat higher values in late summer for the year 2003.
\end{abstract}

\section{Introduction}

Spectral ultraviolet (UV) global and diffuse irradiances on an horizontal plane have been routinely measured during several years at the Briançon station in the French Southern Alps. The direct irradiance is therefore obtained by difference, and is used for retrieving AODs. The objectives are: i) to build a climatology of aerosols in a clean unpolluted area, ii) to detect possible cases of turbidity and to analyse their causes.

We present the measurement site and the instruments in Sect. 2, the data and their analysis in Sect. 3. Section 4 shows the results, mainly the AOD annual variation. Summary and conclusion are in Sect. 5.

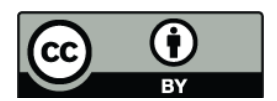

Correspondence to: J. Lenoble (jacqueline.lenoble@wanadoo.fr)

\section{Station and instruments}

The measurement site is located in Villars Saint Pancrace, a small village, close to the town of Briançon $\left(44.90^{\circ} \mathrm{N}\right.$, $6.65^{\circ} \mathrm{E}$ ), in a sunny and dry Alpine valley, at the altitude of $1310 \mathrm{~m}$ a.s.l.; the site belongs to the CEMBREU. The instruments are operated under the supervision of LOA and IRSA groups. Figure 1 shows a photograph of the instruments on the CEMBREU platform.

Two UV spectroradiometers measure the irradiance on an horizontal surface, a Bentham (BE) DM150, and a Jobin Yvon (JY) HD10. Both instruments operated regularly since November 1999, until September 2005. The BE measures every $30 \mathrm{~min}$ three spectra, alternately the global, with a shadow disc the diffuse and the global irradiance; each spectral scan needs about 5 min The JY first measured the global irradiance every $30 \mathrm{~min}$ (Pachart, 1997; Masserot, 2001); it was equipped with a shadow disc in July 2003, and thereafter measured a spectrum every $10 \mathrm{~min}$, alternately global and diffuse irradiances. The characteristics of the two instruments are very similar (Lenoble et al., 2005). The largest wavelength recorded is $400 \mathrm{~nm}$ for the BE and $450 \mathrm{~nm}$ for the JY.

Both instruments are calibrated about every 3 months with a standard lamp traceable to NIST. They have taken part into instrument intercomparisons (Gröbner et al., 2000; de La Casinière et al., 2005); their uncertainty is assumed to be around 5\%. The data of the two instruments are processed completely independently; several comparisons of the measured irradiances confirm an agreement between the two instruments within $\pm 5 \%$. The error on the diffuse irradiance

Published by Copernicus Publications on behalf of the European Geosciences Union. 


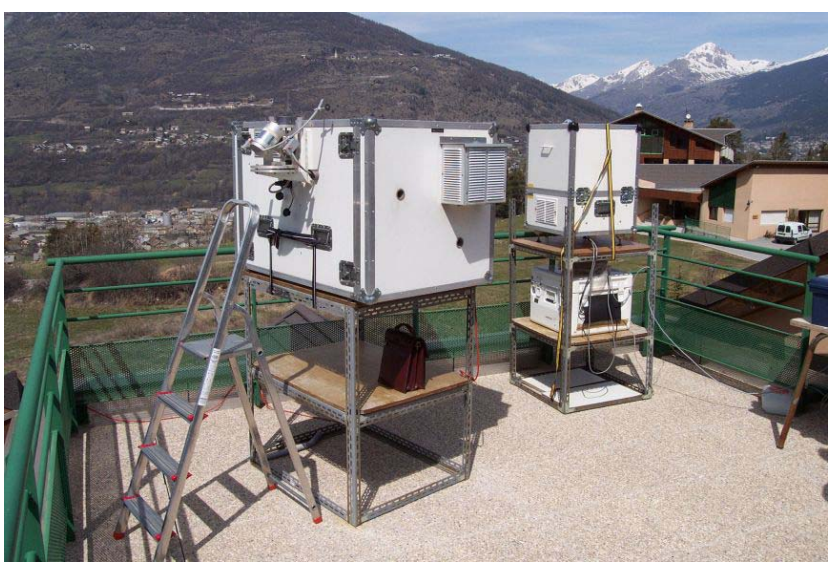

Fig. 1. The measurement platform, with the two spectroradiometers, on the left Bentham, on the right Jobin Yvon.

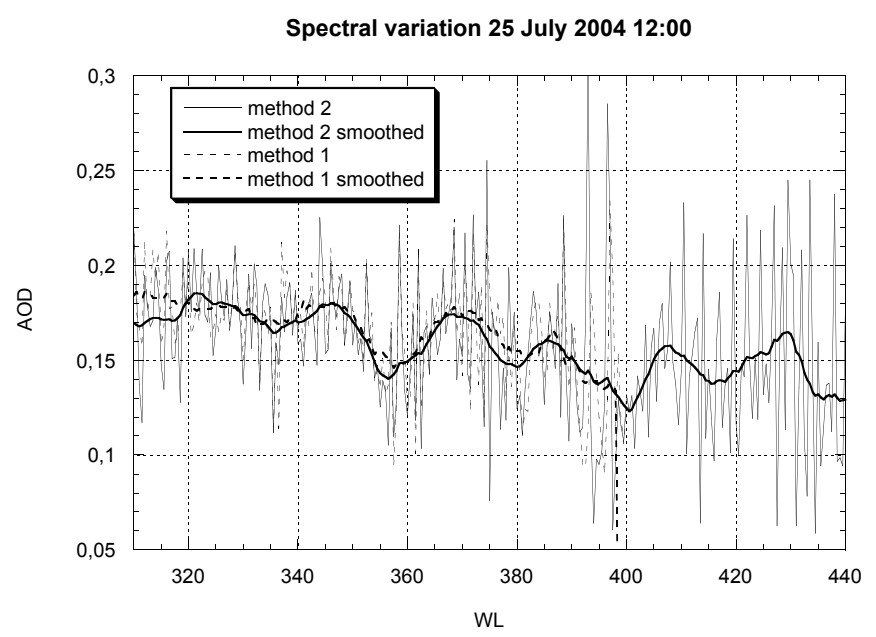

Fig. 2. Spectral variation of AOD observed on 25 July 2004 at 12:00, directly and after smoothing over $4 \mathrm{~nm}$. Solid line for AOD obtained by the method used throughout the paper (method 1), dashed line for the second method presented in Sect. 3.1. The smoothing is performed respectively with a rectangular function, and with a triangular function, for methods 1 and 2 .

due to the sky light intercepted by the shadowing disc has been evaluated previously to be smaller than $1 \%$ in the conditions of Briançon site.

A cosine correction is applied to both instruments; however it is important only for large solar zenith angles, and we do not consider such cases in this study.

The direct solar irradiance $\operatorname{DIR}(t)$ at time $t$, is retrieved from the measured global GLO and diffuse DIF irradiances, as

$\operatorname{DIR}(t)=[\mathrm{GLO}(t+\Delta t)+\operatorname{GLO}(t-\Delta t)] / 2-\operatorname{DIF}(t)$

where $\Delta t=10 \mathrm{~min}$, for the JY and $\Delta t=5 \mathrm{~min}$ for the BE. The retrieval is limited to clear stable conditions, when the so-

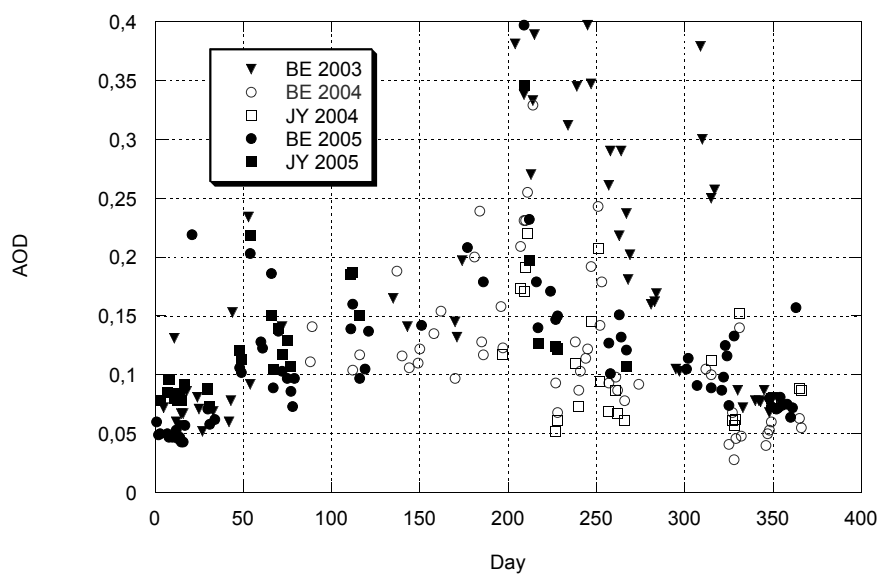

Fig. 3. The annual variation of AOD at $340 \mathrm{~nm}$, for the two instruments, and the three years 2003, 2004, 2005.

lar zenith angle (SZA) does not vary too rapidly, preferably around local noon.

\section{Retrieval of the AOD}

\subsection{Method}

The direct irradiance can be written, as

$\mathrm{DIR}=F_{0} \mu_{0} \exp \left(-\left(\tau_{\text {Ray }}+\tau_{\mathrm{Oz}}+\tau_{\mathrm{aer}}\right) / \mu_{0}\right)$,

where $F_{0}$ is the extraterrestrial solar flux, $\mu_{0}$ the cosine of the SZA, $\tau_{\text {Ray }}$ the molecular Rayleigh optical depth, $\tau_{\mathrm{Oz}}$ the ozone absorption optical depth, $\tau_{\text {aer }}$ the AOD. The $\mathrm{NO}_{2}$ optical depth has been checked to be negligible. The AOD is the only unknown in Eq. (2). The direct irradiance that would be observed for a perfectly clear atmosphere, without aerosols, $\mathrm{DIR}_{c l}$, is computed as

$\operatorname{DIR}_{c l}=F_{0} \mu_{0} \exp \left(-\left(\tau_{\text {Ray }}+\tau_{\mathrm{Oz}}\right) / \mu_{0}\right)$,

at step $0.05 \mathrm{~nm}$, using the ATLAS3 high resolution spectrum (Van Hoosier, 1996), and it is convoluted using the instrument slit function. The Rayleigh optical depth is computed for a standard mid latitude atmosphere winter or summer (McClatchey et al., 1972), at the altitude of Briançon. The ozone optical depth uses the Paur and Bass (1985) ozone cross sections and the ozone total column amount given by the Total Ozone Mapping Spectrometer (TOMS) (McPeters et al., 1998), for Briançon.

The AOD is therefore retrieved as

$\tau_{\mathrm{aer}}=-\mu_{0} \ln (\mathrm{DIR} / \mathrm{DIR} c l)$.

A similar approach consists in first deriving the total optical depth

$\tau_{\mathrm{tot}}=\tau_{\mathrm{Ray}}+\tau_{\mathrm{Oz}}+\tau_{\mathrm{aer}}$ 


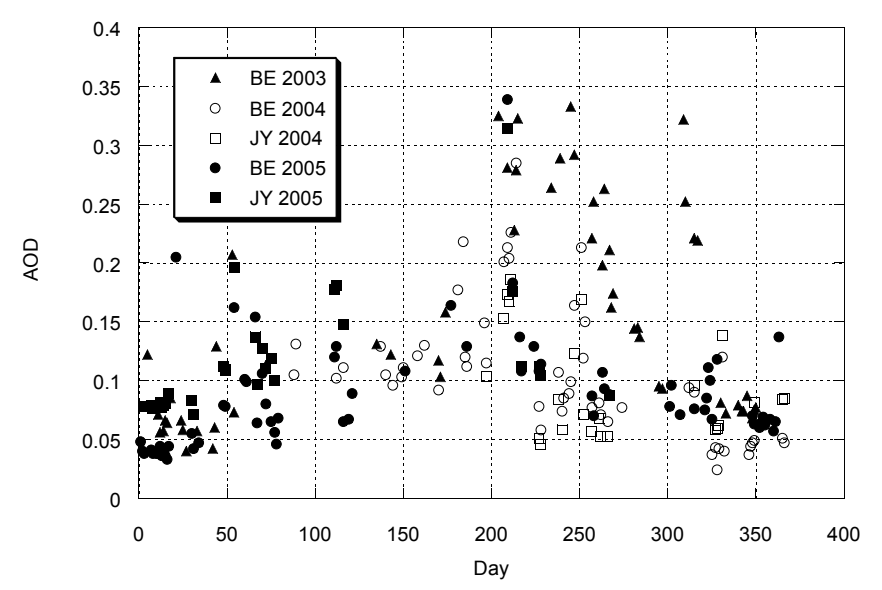

Fig. 4. Same as Fig. 3 for $380 \mathrm{~nm}$.

from Eq. (2), as

$\tau_{\text {tot }}=-\mu_{0} \ln \left(\mathrm{DIR} / \mu_{0} F_{0}\right)$,

where $F_{0}$ is preliminary convoluted to the instrument slit function; then $\tau_{\text {Ray }}$ and $\tau_{\mathrm{Oz}}$ are substracted from $\tau_{\text {tot }}$. This second method has been compared satisfactorily (Fig. 2) to the first one, used throughout the paper. The differences, which appear similarly in all cases, are most likely due to the different slit corrections and to the different smoothing performed in both methods.

\subsection{Data analyzed}

All the cloudless days available for the three years 2003, 2004, and 2005, are considered. We select cloudless days by plotting the diurnal variation of irradiance at a fixed wavelength; the curve is perfectly regular only when there is no cloud. Both instruments suffered some technical problems leading to interruptions of data recording. The JY spectroradiometer operated, with the shadow disc, only between July 2004 and September 2005. On the whole 179 cloudless days have been analyzed, including 53 days with the two spectroradiometers. Some preliminary results concerning only the JY data have been presented (Guirado et al., 2005).

A previous analysis of the BE data in 2001 and 2002 has been published (Lenoble et al., 2004), and its results are comforted by the present work.

\subsection{Uncertainties}

For this analysis, we have found more convenient to use the formalism of the second method, although both methods are rigourously equivalent.

From (Eq. 6), the uncertainty on $\tau_{\text {tot }}$ is due to the independent uncertainties on the measured irradiance DIR and on the extraterrestrial flux $F_{0}$.

$\Delta \tau_{\text {tot }}=\mu_{0}\left[(\Delta \mathrm{DIR} / \mathrm{DIR})^{2}+\left(\Delta F_{0} / F_{0}\right)^{2}\right]^{1 / 2}$

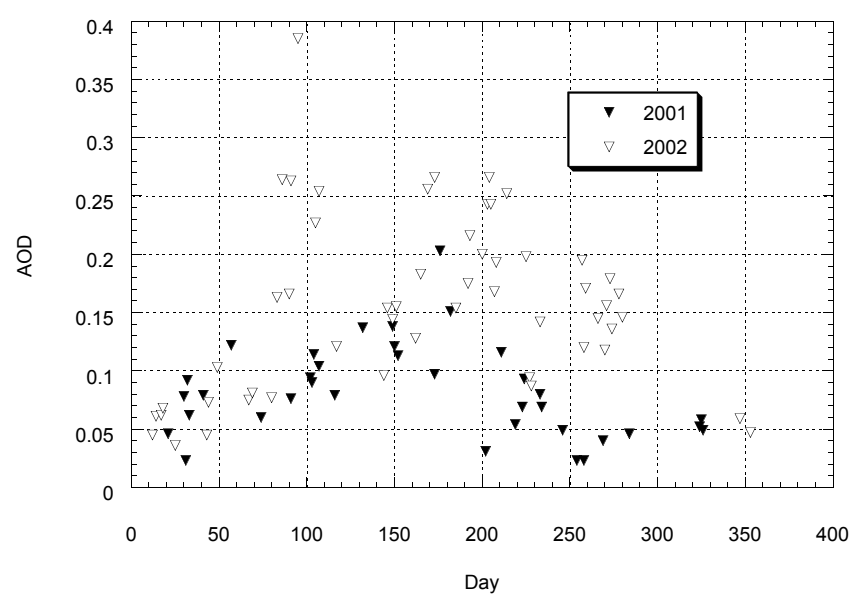

Fig. 5. Annual variation of average UV-A AOD for 2001 and 2002, from Fig. 2 in Lenoble et al. (2004).

On $\tau_{\text {aer }}$ retrieved from Eq. (5), further uncertainties are added by the uncertainties on $\tau_{\mathrm{Ray}}$, and $\tau_{\mathrm{Oz}}$. We will try briefly to analyze these various causes of error.

The uncertainties on the measurements of either GLO or DIF have been discussed by several authors (Bernhard and Seckmeyer, 1999; Houët, 2003; Webb et al., 1998). Roughly half of the uncertainty is due to the calibration itself, both to the lamp calibration uncertainty, and to the uncertainties during the calibration procedure. Another half of the error comes from the measure, as instrument noise, cosine error of the diffusor, wavelength shift non perfectly corrected. Houët (2003) estimates the measurement uncertainty to about 4$5 \%$ for a confidence interval of $95 \%$. The error becomes larger when the signal is small, i.e. at short wavelengths, and when the sun is low on the horizon. On the direct irradiance DIR, a further error could come from the averaging process in Eq. (1); however, it is negligible for wavelengths larger than $310 \mathrm{~nm}$, and SZA smaller than $60^{\circ}$ (Houët, 2003). We have limited our analysis to these conditions.

The different extraterrestrial spectra measured by various instruments (Cebula et al., 1999), differ by about $2-3 \%$, which suggest a possible systematic error of about $2 \%$ on $F_{0}$. From Eq. (7)

$\Delta \tau_{\text {tot }}=0.055 \mu_{0}$,

varying between 0.050 for a high sun to 0.025 for a sun at $60^{\circ}$ from the zenith; actualy, the influence of $\mu_{0}$ in Eq. (8), can be partly compensated, because the measurement uncertainty increases for low sun, as mentionned above.

On $\tau_{\text {Ray }}$, there are two causes of uncertainty, one on the Rayleigh cross-sections, due to the uncertainties on the depolarization factor, and on the air refractive index (Bodhaine et al., 1999), and another one due to the uncertainty on the 


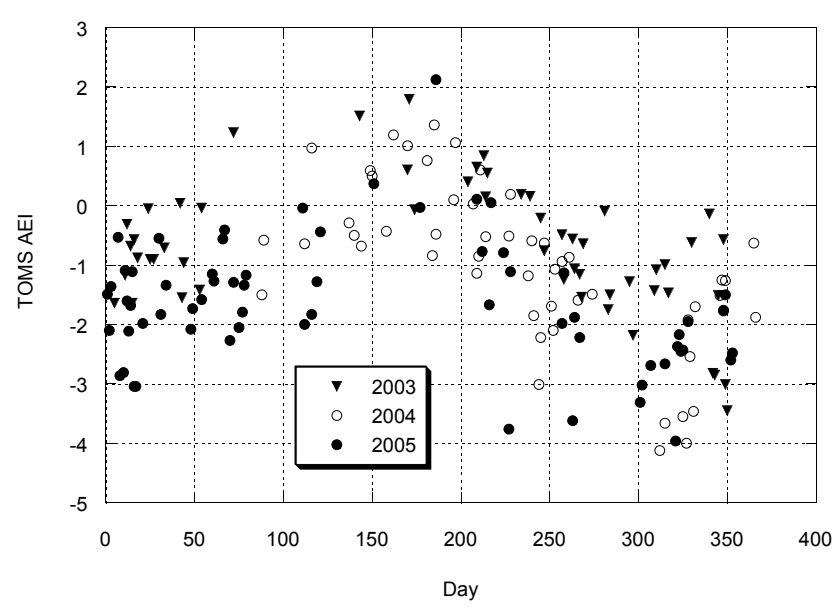

Fig. 6. TOMS Aerosol Index for cloudless days, in 2003, 2004, 2005.

surface pressure; these independent errors can be estimated respectively to about $2 \%$ and $1.5 \%$, leading to

$\Delta \tau_{\text {Ray }}=0.025 \times \tau_{\text {Ray }}$.

For $320 \mathrm{~nm}, \Delta \tau_{\text {Ray }}=0.020$; it decreases toward large wavelengths to 0.008 at $400 \mathrm{~nm}$.

Similarly on $\tau_{\mathrm{Oz}}$, the uncertainty is due to the uncertainty on the ozone cross-sections (about 2\%), and on the ozone total column amount evaluated to about $4 \%$ for TOMS data; this leads to

$\Delta \tau_{\mathrm{Oz}}=0.045 \times \tau_{\mathrm{Oz}}$

This error increases sharply with $\tau_{\mathrm{Oz}}$ towards short wavelengths, but it becomes completely negligible above $330 \mathrm{~nm}$.

This is a further reason to limit our analysis to a wavelength range with a lower limit between 310 and $330 \mathrm{~nm}$.

Roughly, we estimate the uncertainty on AOD to be around 0.05 , knowing that it slightly varies with wavelength and with SZA. For the small AOD observed in Briançon (0.1-0.3), this means a large relative uncertainty, reaching $50 \%$ for the smallest values.

\section{Results}

Despite the correction of wavelength shift performed on the measured spectra, and the convolution of the high resolution solar spectrum, the spectral variation of AOD shows strong rapid oscillations, obviously erratic, and it has been smoothed over $4 \mathrm{~nm}$, either with a rectangular or with a triangular function. After smoothing, some large oscillations remain (Fig. 2); definitively, they are artefacts, and not real spectral variations. We did not find a satisfactory explanation for these oscillations, which are of the order of the expected error. The AOD slowly increases toward short wavelengths

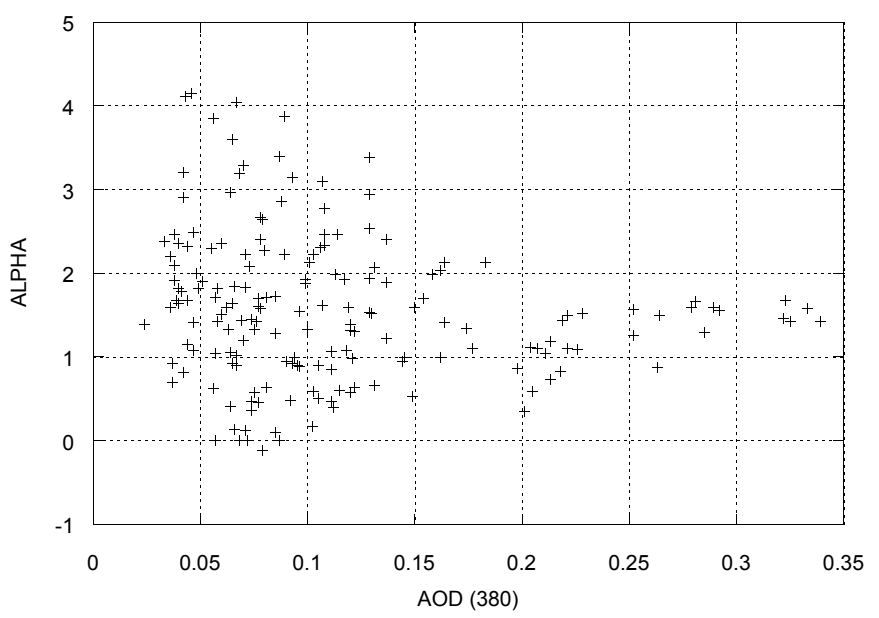

Fig. 7. Angström parameter $\alpha$ versus AOD at $380 \mathrm{~nm}$, for the three years 2003, 2004, 2005; $\alpha$ is estimated between 340 and $380 \mathrm{~nm}$.

between $440 \mathrm{~nm}$ and $320 \mathrm{~nm}$; as said before, the uncertainty becomes too large below $320 \mathrm{~nm}$ to allow analysis. When results are obtained from the two instruments on the same day, they always agree wihin $\pm 3 \%$, that is better than the estimated uncertainty of $\pm 5 \%$.

We have therefore decided to focus on analyzing time variations, more precisely annual variations at 12:00 TU, which is not far (within about half an hour) from local noon, at two specific wavelengths. The wavelengths chosen are $340 \mathrm{~nm}$ and $380 \mathrm{~nm}$, which correspond to the UV channels of the CIMEL sunphotometer of the AErosol RObotic NETwork (AERONET) (Holben et al., 1998).

\subsection{Annual variations}

Figure 3 presents the AOD annual variations at wavelength $340 \mathrm{~nm}$ obtained from both instruments for the three years 2003, 2004, and 2005.

A general behaviour appears for the three years, with low values, smaller than 0.1 , in winter, and higher values, generally around 0.2 , in summer. Some much higher values, around 0.3-0.4, appear between mid-July to mid-September; they are much more numerous, and still appear late October, in 2003, which was characterized by a very hot summer. For all the three years, the increase after the low winter values begins in mid-February, and the decrease in mid-November. Even considering the large relative uncertainty mentionned above, the annual variation is significant.

The larger values observed during the hot summer 2003 are in agreement with the ongoing studies performed in the European project GEMS (Global Earth's system Monitoring using in situ and Satellite data), which also find a higher turbidity during this 2003 heat wave.

Table 1 summarizes the results per two month periods. Both the mean and the rms clearly show the general annual 
pattern. The rather large std is due partly to the uncertainty and partly to real day to day variations.

As expected a similar behaviour is observed for $380 \mathrm{~nm}$ (Fig. 4), with values slightly smaller than at $340 \mathrm{~nm}$.

We had previously analyzed the Bentham data for 2001 and 2002 (Lenoble et al., 2004), and presented an average AOD in the UV-A, whereas we present in this paper AODs at 340 and $380 \mathrm{~nm}$. We have already stated that AOD varies only slowly in the wavelength range $320-400 \mathrm{~nm}$. Therefore the previous results can be compared qualitatively to the present ones. In Fig. 5, we have reported the results from Fig. 2 in Lenoble et al. (2004); it confirms a similar pattern, with low winter values, and higher summer values in 2001 and 2002, as in 2003, 2004, and 2005. This behaviour seems typical of Briançon site over five years.

\subsection{Complementary analysis}

The satellite instrument TOMS (McPeters et al., 1998) provides regularly an aerosol index (AI), which is related to the aerosol optical depth and absorption in a rather complex way. The retrieval of AI from TOMS observations, and its analysis in term of aerosol characteristics, have been described in several publications (Herman et al., 1997; Torres et al., 2002). We consider it here only as a qualitative parameter, and we present in Fig. 6, TOMS AI for the Briançon site on the clear days of 2003, 2004, and 2005. Surprisingly or not, the AI annual variation shows some similarity with the AOD behaviour; positive AIs in summer could point to absorbing aerosols. Trying to push forward the comparison would be risky.

As we have seen (Fig. 2), the spectral variation of $\tau_{\text {aer }}$ is weak, with oscillations, and we can look only for an approximate information on the general slope. We have chosen, as reference, an Angström parameter $\alpha$ defined between 340 and $380 \mathrm{~nm}$. Figure 7 shows $\alpha$ plotted versus $\tau_{\text {aer }}(380)$ for all the BE data. For small AODs, the average value of $\alpha$ is 1.7 , with a very large dispersion, mostly due to the uncertainties on AODs; when $\tau_{\text {aer }}$ becomes larger than $0.2, \alpha$ tends to stabilize around 1.3 , with a std of 0.35 , suggesting that particles could be larger and more homogeneous, when it is more turbid.

\section{Discussion and conclusion}

The main outcome of this work is an annual variation of AOD, with low winter values, around 0.1 or smaller, at $340 \mathrm{~nm}$, and much larger summer values, reaching 0.3-0.4, with an average of 0.2 , at $340 \mathrm{~nm}$. This behaviour is observed at all wavelengths between $320-400 \mathrm{~nm}$, the spectral variation being weak over this limited interval. It is observed for the five year period from 2001 to 2005 , with the largest summer values in 2003 , and it is definitively significant despite the large relative uncertainty.
Table 1. Statistical results for $\tau_{\text {aer }}(340 \mathrm{~nm}), 3$ Years, 2 Instruments. For $N$ measures $x_{i}$ of a quantity $x$, mean $=X=\frac{1}{N} \sum_{i=1}^{i=N} x_{i}$; $\mathrm{rms}=\sqrt{\frac{\sum_{i=1}^{i=N} x_{i}^{2}}{N}} ; \mathrm{std}=\sqrt{\frac{\sum_{i=1}^{i=N} x_{i}^{2}-N X^{2}}{N-1}}$.

\begin{tabular}{lcccc}
\hline Period & Point number & Mean & rms & std \\
\hline Jan-Feb & 51 & 0.086 & 0.097 & 0.046 \\
Mar-Apr & 28 & 0.125 & 0.129 & 0.030 \\
May-Jun & 16 & 0.147 & 0.151 & 0.035 \\
Jul-Aug & 44 & 0.194 & 0.217 & 0.097 \\
Sep-Oct & 40 & 0.156 & 0.175 & 0.079 \\
Nov-Dec & 53 & 0.097 & 0.116 & 0.065 \\
\hline
\end{tabular}

The increase of turbidity in spring can be due to the vegetation, pollen and other vegetal particles in summer. Another contribution can be dust particles, originating from the dry soil in summer, whereas the ground is generally covered with snow in winter.

The few cases with the highest turbidity, could have other more specific explanations, as an arrival of desert dust particles, which sometimes reach the Alps, after crossing the Mediterranean Sea. Another source could be biomass burning particles, from the frequent forest fires in the South of France. An analysis of these events and of the air mass trajectories would be necessary to check the above hypothesis.

Acknowledgements. The authors acknowledge the help provided by the Director and the technicians of the CEMBREU.

Funding was provided by the European Union, under the three successive contracts SUVDAMA, EDUCE, and CUVRA.

Edited by: M. Blumthaler

\section{References}

Bernhard, G. and Seckmeyer, G.: Uncertainty of measurements of spectral solar UV irradiance, J. Geophys. Res., 104, $14321-$ 14345, 1999.

Bodhaine, B. A., Wood, N. B., Dutto, E. G., and Slusser, J. R.: On Rayleigh optical depth calculations, J. Atmos. Oceanic Technol., 16, 1854-1861, 1999.

Cebula, R. P., Thuillier, G. O., VanHoosier, M. E., Hilsenrath, E., Herse, M., Brueckner, G. E., and Simon, P. C.: Observations of the solar irradiance in the $200-350 \mathrm{~nm}$ interval during the ATLAS-1 mission: a comparison among three sets of measurements-SSBUV, SOLSPEC, and SUSIM, Geophys. Res. Lett., 23, 2289-2292, 1996.

de La Casinière, A., Cachorro, V., Smolskaia, I., Lenoble, J., Sorribas, M., Massot, O., Anton, M., and Vilaplana, J. M.: Compartive measurements of total ozone amount and aerosol optical depth during a campaign at El Arenosillo, Huelva, Spain, Ann. Geophys., 23, 3399-3406, 2005, http://www.ann-geophys.net/23/3399/2005/. 
Gröbner, J., Albold, A., Blumthaler, M., Cabot, T., de La Casinière, A., Lenoble, J., Martin, T., Masserot, D., Müller, M., Philipona, R., Pichler, T., Pougatch, E., Rengarajan, G., Schmucki, D., Seckmeyer, G., Sergent, C., Touré, M. L., and Weihs, P.: Variability of spectral solar ultraviolet irradiance in an Alpine environmennt, J. Geophys. Res., 105, 26 991-27 003, 2000.

Guirado, F., Lenoble, J., de La Casinière, A., Cabot, T., and Brogniez, C.: The aerosol ultraviolet optical depth observed at a station in the French Southern Alps, Proceedings of SPIE, 5979, 59791L-1-L-10, 2005.

Herman, J. R., Bhartia, P. K., Torres, O., Hsu, C., Seftor, C., and Celerier, E.: Global distribution of UV-absorbing aerosols from Nimbus 7/TOMS data, J. Geophys. Res., 102, 16911-16922, 1997.

Holben, B. N., Eck, T. F., Slutsker, I., Tanré, D., Buis, J. P., Setzer, A., Vermote, E., Reagan, J. A., Kaufman, Y., Nakajima, T., Lavenu, F., Jankowiak, I., and Smirnov, A.: AERONET A federated instrument network and data archive for aerosol characterization, Rem. Sens. Environ., 66, 1-16, 1998.

Houët, M.: Spectroradiometrie du rayonnement solaire UV au sol: Améliorations apportées à l'instrumentation et au traitement des mesures: Analyse pour l'évaluation du contenu atmosphérique en ozone et en aérosols, $\mathrm{PhD}$ thesis Université des Sciences et Technologies de Lille, 2003.

Lenoble, J., de La Casinière, A., and Cabot, T.: Analysis of direct solar ultraviolet irradiance measurements in the French Alps: Retrieval of turbidity and ozone column amount, Appl. Optics, 43, 3133-3139, 2004.

Lenoble, J., Brogniez, C., Houët, M., Legrand, M., de La Casinière, A., Cabot, T., and Guirado, F.: The French network for spectral measurement of solar UV irradiance, in: IRS 2004: Current Problems in Atmospheric Radiation, edited by: Fischer, H. and Sohn, B. J., 359-362, 2005.
McClatchey, R. A., Fenn, R. W., Selby, J. E. A., Volz, F. E., and Garing, J. S.: Optical properties of the atmosphere, ERP 411, AFCRL-72-0497, 1972.

McPeters, R., Barthia, P. K., Krueger, A. J., Herman, J. R., Wellemeyer, C. G., Seflor, C. J., Jarros, G., Torres, O., Moy, L., Labow, G., Byerly, W., Taylor, S. L., Swissler, T., and Cebula, R. P.: Earth Probe Total Ozone Mapping Spectrometer (TOMS) Data Products User's Guide, NASA/TP-1998-206895, 1998.

Masserot, D.: Spectroradiometrie du rayonnement solaire UV: Mesures et analyses, $\mathrm{PhD}$ thesis Université des Sciences et Technologies de Lille, 2001.

Pachart, E.: Mesures et modélisation du rayonnement ultraviolet au sol, $\mathrm{PhD}$ thesis Université des Sciences et Technologies de Lille, 1997.

Paur, R. J. and Bass, A. M.: The ultraviolet cross sections of ozone. II, Results and temperature dependence, in: Atmospheric Ozone, Proceedings of the Quadriennal Ozone Symposium, edited by: Zerefos, C. S. and Ghazi, A., 611-616, 1985.

Torres, O., Bhartia, P. K., Herman, J. R., Sinyuk, A., Ginoux, P., and Holben, B.: A long-term record of aerosol optical depth from TOMS observations and comparison to AERONET measurements, J. Atmos. Sci., 59, 398-413, 2002.

Van Hoosier, M. E.: The ATLAS-3 solar spectrum, available via: http://www.srrb.noaa.gov/pub/users/irina/OUT/UMKEHR/ STAS, 1996.

Webb, A. R., Gardiner, B. G., Martin, T. J., Lesczynski, K., Metzdorf, J., Mohnen, A., and Forgan, B.: Guidelines for site quality control of UV monitoring, Environ. Pollut. Monit. Res. Programme, WMO, Rep. Ser. 126, 1998. 